\title{
¿POR QUÉ NO PROSPERA EL DIÁLOGO CIVIL-MILITAR EN EL ECUADOR?
}

\author{
Dra. Bertha García Gallegos *
}

\section{INTRODUCCIÓN}

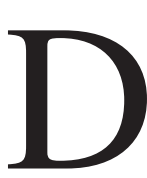

esde enero de 1997, el Proyecto Relaciones Civil-Militares organizado por la Pontificia Universidad Católica del Ecuador ${ }^{1}$, juntamente con la Escuela de Relaciones Internacionales de la Universidad Americana (Washington USA) iniciaron un proceso de diálogo con las Fuerzas Armadas. Pero el acercamiento de las dos instituciones académicas a la institución armada empezó antes de la guerra no declarada con el Perú que estalló entre diciembre de 1995-febrero de 1996, pero ningún resultado se obtuvo del ministro de Defensa de entonces. Concluida la "Guerra del Cenepa", el general Paco Moncayo, conductor estratégico del evento por parte del Ecuador, luego Comandante de la fuerza terrestre y posteriormente Jefe del Comando Conjunto, posibilitó la realización de los diálogos que se extendieron durante dos años consecutivos. En ellos participaron junto con ciudadanos representativos del ámbito académico, periodistas, empresarios, dirigentes sindicales, las promociones de coroneles superiores y tenientes coroneles estudiantes de la Academia de Guerra del Ejército de entonces. En Guayaquil se realizó un seminario especial con oficiales de la Marina.

El 7 de febrero de 1998, ocurrió el defenestramiento, por el Congreso, del Presidente Abdalá Bucaram Ortiz. Los diarios del país son testigos de la presión popular a la que sometieron al presidente del Comando Conjunto, Paco Moncayo, para que asumiera el poder. Si bien los análisis posteriores indican que hubo una suer-

\section{* Directora del Programa Relaciones Civil-Militares- PUCE}

Todas las discusiones constan en los libros editados por el Proyecto: DIÁLOGO CIVIL MILITAR Y ¿QUÉ ESPERA EL ECUADOR, HOY, DE LAS FUERZAS ARMADAS? Quito, PUCE. 
te de arbitraje militar en la solución del impasse del poder, tal hecho se debió más bien a la relación específica de las circunstancias que tejió un entrelazamiento entre la solución presentada por los militares y la del Congreso. No podría afirmarse que existió un acto de usurpación de tareas políticas por parte del Jefe del Comando Conjunto. Ocho días antes, en un acto público, propiciado por el Programa, el general Moncayo había afirmado la necesidad de que los militares se mantuvieran en sus funciones constitucionales.

El 21 de enero de 2000, ninguno de los oficiales registrados en las discusiones que lideró la PUCE durante esos dos años en que se mantuvo el diálogo, estuvieron implicados en el golpe de Estado en el que participaron coroneles y otros oficiales inferiores pertenecientes especialmente a la fuerza terrestre. No queremos señalar con esto que el diálogo tuviera una incidencia directa en la no participación de los oficiales en un evento golpista. Lo que sí queremos enfatizar es que el diálogo no tuvo efectos politizantes dentro de las Fuerzas Armadas, como se quiso dar a entender meses después por parte del Ministro Unda y sus asesores. Desde cualquier ángulo que se lo mire el diálogo sigue siendo un proceso con un enorme potencial de fortalecer las instituciones e inducir a una dinámica de fluidez en las relaciones que requiere el funcionamiento del Estado de derecho.

Ahora constatamos que la suerte de "diálogo paralelo" entre las partes partió de perspectivas absolutamente distintas ${ }^{2}$. Una crítica

\footnotetext{
'Fernando Bustamante: "Las dificultades de la sociedad en la formulación de políticas de Seguridad y Defensa" en: EL PODER MILITAR AMÉRICA LATINA Y ECUADOR. PRCMPUCE, en próxima publicación. "Esta preocupación ha estado asociada a consideraciones normativas centradas en dos ejes fundamentales: la profundización del control civil democrático sobre las FFAA, y la búsqueda de mecanismos "objetivos" que prevengan la aparición de desfases entre las mentalidades políticas y las culturas cívicas de ambas partes. ... se ha considerado que el control civil sobre las FFAA deja mucho que desear, por dos factores primordiales: las continuas intervenciones de los militares en decisiones políticas cruciales o en actividades golpistas y lo que se considera excesiva autonomía o tutelaje militar en el manejo de áreas cruciales de la vida nacional. En todo caso, se constata la desviación que tiene el sistema de relaciones entre el poder civil y el poder militar en relación al patrón prevaleciente en las democracias "maduras" del primer mundo. Este modelo constituye un referente central en las motivaciones de los impulsores nacionales y extranjeros del diálogo civil- militar.
} 
retrospectiva que necesariamente debemos hacernos quienes condujimos el proceso, es que el diálogo no avanzó por los caminos adecuados para ayudar a deshacer el embrollo político y jurídico con el que el débil desarrollo institucional del Estado ecuatoriano colocó a la "sociedad civil"y a la "sociedad militar"en ángulos opuestos, desconocidos y a veces enfrentados entre sí. El objetivo inicial fue propiciar un acercamiento, cualquiera que fuere, $y$ lo encontramos en una metodología que proponía la discusión en torno a temas comunes a todos: el desarrollo para un país pequeño como el nuestro, su vinculación al desarrollo mundial, la política; pero no hablamos de las Fuerzas Armadas específicamente.

Años después, hemos entendido que un diálogo con las Fuerzas Armadas debe enfocarse sobre sus asuntos específicos. Sobre lo que es pertinente al ámbito político que comparten civiles y militares: las políticas de defensa, de seguridad y militar. En este trabajo nos empeñamos en hacer un análisis del campo de conocimiento que concierne a un verdadero diálogo civil-militar para que pueda contribuir al fortalecimiento institucional del Estado y la sociedad. ¿De qué hablamos cuando nos referimos a las relaciones civil-militares?

\section{LAS RELACIONES CIVIL-MILITARES, LA POLÍTICA Y EL ES- TADO}

La necesidad de usar la fuerza en sus diversas formas para la sobrevivencia y organización de las sociedades, es tan antigua como la historia misma. Su desarrollo ha estado supeditado al grado de evolución de la organización social en naciones y estados. Pero ha sido la política el instrumento de organización social que transformó, institucionalizó, subordinó y legitimó a la fuerza, para construir un orden social bajo una forma moral y jurídica.

En cambio, las preocupaciones de los participantes militares parecen centrarse más bien en otras motivaciones. El diálogo con representantes civiles de las academias locales e internacionales, con organizaciones de defensa de los derechos humanos y con dirigentes gremiales, se presenta más bien como parte de un esfuerzo de legitimación de las fuerzas, por un lado, y por otro, como parte de una pedagogía a través de la cual, el estamento militar difunde entre los legos las cosmovisiones básicas de su profesión". 
Max Weber, el gran teórico alemán de la sociedad moderna, expresa esta relación en su concepto de Estado: "El Estado es una asociación jurídica, de administración política, que detenta el monopolio legítimo de la violencia, para que un orden jurídico prevalezca".

Una función básica del Estado es proporcionar seguridad, defender el patrimonio territorial y bienes de los ciudadanos, y propender a la estabilidad interna de la sociedad. Este es el papel especializado de los cuerpos armados. En el estado de derecho esta función, esencialmente instrumental, está subordinada a su objetivo primordial: garantizar los derechos de libertad, justicia y paz.

Las relaciones civil-militares son esencialmente políticas y demuestran la existencia de una tensión; constituyen una relación inestable de fuerza entre quienes detentan el poder directo de las armas y los gobiernos que representan la autoridad del Estado. Son también un producto de la multiplicidad y complejidad de las tareas que debe resolver el Estado y de la división y de la especialización del trabajo para propender a su propia estabilidad y permanencia, así como al bienestar y desarrollo de la sociedad. Machiavello, en su libro "El Arte de la Guerra"definió a esta como una relación entre elites: "una relación entre quienes suben al gobierno, para lo cual deben usar la fuerza física y aquellos que la tienen". "Los gobiernos necesitan a las Fuerzas Armadas para regular la política exterior y salvaguardar el orden interno" 4 .

Es posible que la relación "entre elites militares y gobiernos" sea una definición más cercana a la realidad de las relaciones civil-militares. Las tensiones socio económicas contribuyen al debilitamiento de los gobiernos y ponen a prueba la capacidad de sus liderazgos. En esos contextos las corporaciones armadas, pueden sobrepasar sus funciones y asumir un carácter político: el "militarismo" es el fenómeno que expresa este desbordamiento institucional. Las fuerzas armadas tienden también a constituirse como entidades "autónomas", con un funcionamiento aislado de la auto-

\footnotetext{
${ }^{3}$ Adalberto Agozino. Estrategia y Acción Militar.

${ }^{4}$ Alfred Stepan, Brasil: Los Militares y la Política, Buenos Aires, Amorrortu, $p 73$.
} 
ridad civil. Se convierten en entidades "corporativas" cuando priman más los intereses de tipo laboral y social y menos los intereses institucionales relacionados con sus deberes constitucionales. Estos fenómenos constituyen una fuente de inestabilidad y desorganización de la institución y del Estado.

Los estudios actuales consideran que una condición importante para mantener el equilibrio social es aumentar la capacidad de las instituciones políticas que concurren a la formación y supervisión de los gobiernos, y son los instrumentos especializados para la organización política. Los partidos constituyen el punto de apoyo para instrumentar una política de administración democrática de la fuerza y resolver los problemas de la seguridad en función de los objetivos del Estado. "La política pública relativa al manejo del conflicto es la política de las políticas, la que es soberana", dice Lucien Goldman, de los "Conflictos Armados a las Soluciones Políticas" ${ }^{5}$.

Esta reflexión nos lleva a completar la definición de relaciones civil-militares, como una realidad esencialmente política pero también como una ciencia, una perspectiva teórica que permite analizar, de manera comparativa, el grado de desarrollo de las instituciones y organizaciones políticas, desde el punto de vista de su capacidad para administrar las necesidades de la seguridad en función de los objetivos del Estado: garantizar los derechos ciudadanos en condiciones de paz, libertad y justicia. La clave aquí es lo que llamamos "control democrático de la fuerza".

\section{FORMAS HISTÓRICAS DE LAS RELACIONES CIVIL-MILITA- RES}

Antes de la modernidad, la guerra transcurría ajena a la política y sin comprometer a la población que solo sufría las consecuencias del triunfo o de la derrota del bando de fuerza en cuestión. El pueblo era eventualmente leal con la dinastía reinante; su identidad se relacionaba con su comarca o tierra de origen pero no constituía una verdadera identidad nacional; la gente era ajena a un sentido

\footnotetext{
${ }^{5}$ Lucien Goldman. De los Conflictos Armados las Políticas Partidarias.
} 
de responsabilidad respecto a los asuntos públicos. Los ejércitos no habían desarrollado un espíritu de cuerpo y los oficiales eran aristócratas, movidos por el honor o la gloria personal; los soldados lo eran por la ambición o la aventura.

1. En el siglo XVIII, la Revolución Francesa y la industrialización hicieron realidad la idea que tuvo Machiavello, doscientos años antes y las de los filósofos liberales Montesquieu y Rousseau: e/ ciudadano soldado es el mejor para guardar los intereses de la nación. El Ejército francés napoleónico fue el modelo del Ejército Naciona/difundido por el colonialismo europeo en la formación de los Estados centrales y periféricos hasta la Segunda Guerra Mundial. Desde entonces la guerra ya no estuvo vinculada en intereses dinásticos, sino a una ideología nueva, el nacionalismo, una fuerza hasta entonces desconocida, una pasión, que movía a oficiales y tropas por los ideales de libertad e independencia de la nación.

La inclusión del soldado -ciudadano y la ideología y sentimiento nacional-, junto con las innovaciones tecnológicas (desarrollo de la artillería) crearon nuevas posibilidades estratégicas y tácticas para el comandante en jefe; responsabilidades especializadas para los comandantes subordinados; condujo a una nueva organización del ejército en conjuntos especializados y elevó los niveles de desarrollo del arte y la ciencia de la guerra hasta niveles hasta entonces insospechados para lograr resultados más rápidos y decisivos.

Pero el poder que alcanzó esta máquina militar amenazó con ser desequilibrante del poder del Estado; por ello debía ser institucionalizada y sometida a los controles políticos del Estado, mediante la neutralidad política de los militares, deliberada, consagrada en las normas jurídicas. Surgió así, históricamente, una gran tensión entre las elites civiles que por diversos mecanismos han intentado controlar los asuntos que tienen que ver con la organización, el tamaño, la educación, etc. de los militares; aminorar las tendencias exageradas hacia un aislamiento y hacia un corporativismo demasiado cohesivo de los cuerpos militares, debidos a las razones mismas de su profesionalización que, sin control, los llevaría a obtener espacios cada vez más amplios de autonomía con respecto al estado y a la sociedad. 
La defensa de las naciones, a través del arte de la guerra, se convirtió en una tarea compleja en donde todas las fuerzas de la sociedad y no solo las militares tienen un papel. Produjo y exigió una división de funciones, que implicaron el desarrollo de nuevas capacidades del Estado: el estratega político, el diplomático, el técnico en logística, sanidad, economía de guerra, etc. que deben actuar junto al militar.

El correlato civil de este desarrollo exigía el fortalecimiento de las organizaciones políticas, especialmente los partidos que son los mecanismos específicos para conseguir la legitimación del poder por medio del sufragio universal.

2. La sociedad industrial en el siglo $X X$ produjo también otro modelo de ejército nacional de masas, el socialista, con su correspondiente patrón de relaciones civil-militares. En este modelo el control civil se consigue mediante la incorporación de los oficiales de las Fuerzas Armadas al partido político marxista, mediante la creación de una burocracia política especializada (la figura del COMISARIO Político) inserta en los cuerpos militares para su adoctrinamiento constante y vigilancia. En las sociedades socialistas éste fue considerado también como un mecanismo de integración entre el Ejército y la Sociedad. El militar participa en calidad de ciudadano, a través del partido, en el proceso de toma de decisiones políticas. Ejemplos de este modelo es Cuba en América Latina, México en su momento, China.

3. El modelo profesional de relaciones civil-militares. Luego de la Segunda Guerra Mundial, la aparición del arma nuclear y el altísimo desarrollo tecnológico y científico de la industria armamentista convencional, ha exigido la creación de nuevos, fuertes y eficaces mecanismos para el control político civil de las Fuerzas Armadas e incluso para la conducción política de la guerra. Esto es evidente sobre todo en las potencias nucleares militarmente más desarrolladas como los Estados Unidos y Rusia. El hecho anecdótico que marcó esa transición fue la controversia entre el Presidente Truman y el General MacArthur en torno al uso del arma nuclear en la guerra de Corea. Originó también la presencia del estratega civil, como el eje de una política de neutralización mutua entre las potencias nucleares. La perspectiva de la Guerra Total, propuso la 
preeminencia de la estrategia de disuasión y un nuevo objetivo militar: el alcance o mantenimiento de la paz.

Estos elementos acentuaron el carácter profesional de los ejércitos formados por oficiales y soldados exclusivamente profesionales. Este desarrollo tiende a extenderse hoy también a los ejércitos de las naciones periféricas. Desde comienzos de la década de 1990-1999, la disolución de la Unión Soviética, el neoliberalismo, la globalización, son factores que han empujado un nuevo proceso de modernización y redimensionamiento de los ejércitos nacionales en los países desarrollados. El difícil balance de las economías en las naciones periféricas, la atención especial que deben dar los gobiernos a las necesidades básicas de las poblaciones, en contraste con la necesidad de los países de contar también con Fuerzas Armadas, bien desarrolladas y eficaces, es un factor que contribuye a privilegiar el modelo de ejércitos profesionales cada vez más pequeños y técnicos.

El surgimiento del imperio unipolar y la guerra antiterrorista que estamos observando en estos días nos plantea otros dilemas. Es evidente que el Estado-Nación se está transformando rápidamente y perdiendo espacios de su soberanía. Gran parte de las decisiones económicas y tecnológicas ya no le competen y está cediendo poder a las instituciones internacionales y corporaciones económicas en el plano mundial. Las amenazas a la seguridad de los estados se han diversificado y transnacionalizado, la nueva tecnología de seguridad, altamente especializada no está al alcance de las economía de los estados, exigiendo la formación de alianzas regionales para mantener la seguridad frente a amenazas comunes a varios estados. De allí que es preciso reflexionar sobre los requisitos para potenciar la fuerza del estado nacional de derecho que constituye el único marco relevante en donde es posible el reconocimiento de los derechos ciudadanos y el instrumento y motor de las alianzas económicas y estratégicas para buscar un papel en el mundo globalizado.

La preeminencia del derecho en el marco global, exige mantener una institución militar poderosa no por su tamaño sino por su creciente especialización, bajo el control del gobierno civil. Ello se logra no solo por la construcción de eficaces instrumentos jurídicos 
de control, sino fundamentalmente por la aceptación subjetiva (en sus convicciones morales) y objetiva (basada en la Ley) del militar respecto a su subordinación política. Esto es, en la realización plena de que esta es la condición necesaria para preservar su profesionalización y eficacia. Por su parte, el control civil debe reconocer los espacios de autonomía específica, exclusivamente técnica y profesional de las Fuerzas Armadas. Los dilemas se resuelven conformando reglas de juego claras, sobre el funcionamiento y papeles de los militares. Reglas de juego válidas para contextos de crisis y normalidad, evitando en lo posible la excepcionalidad ${ }^{6}$.

Un problema que presenta el modelo profesional especializado de Fuerzas Armadas es resolver la posible disminución de los canales de integración entre sociedad y fuerzas armadas, si es que el reclutamiento no profesional es anulado. El Estado y la sociedad deben proporcionar tales mecanismos de integración, promoviendo una adecuada cultura política civil interesada en los asuntos militares. Las propias Fuerzas Armadas tienen un papel en esta tarea

\section{AMÉRICA LATINA: ESTADO NACIONAL Y POLITIZACIÓN MILITAR}

Los arriba mencionados modelos de Estado, ejércitos y relaciones civil-militares, que fueron la base de la modernidad, se expandieron al resto del mundo y asumieron características propias según los contextos históricos y culturales. En América Latina, el Modelo Liberal de Relaciones Civil-Militares fue conformado luego de la Independencia, por la acción de los líderes formadores de los estados nacionales y los proyectos de construcción de la nación, que consideraron indispensable institucionalizar un ejército nacional para superar el caudillismo militar que nos agobió durante mucho tiempo. Desde finales del siglo XIX nuestros ejércitos aprendieron la ciencia y el arte de la guerra por parte de las escuelas europeas, inglesa, prusiana o francesa, según los casos; y tomaron de ellas no solo los valores constitutivos y la disciplina, sino también los estilos, la tecnología y hasta los uniformes. Las Constituciones polí-

${ }^{6}$ Esto es, leyes y reglamentos claros, mandatos constitucionales específicos, mecanismos de control y conducción de las Fuerzas Armadas, entre ellos: las Comisiones de Defensa de los Congresos, el desarrollo de los Ministerios civiles de Defensa. 
ticas prescribieron su carácter obediente y no deliberante como correspondía al desarrollo del constitucionalismo propio del estado liberal moderno? ${ }^{7}$.

Muy pronto, un cuerpo institucional semejante, cohesionado por valores, disciplina, mando jerárquico etc., marcó un contraste con el resto de instituciones civiles y políticas, incipientes y caotizadas por las luchas del poder. Como afirma Alain Rouquieu, estudioso de las relaciones civil-militares en América Latina, en casi todos los países, las Fuerzas Armadas fueron convocadas para mediar en los conflictos entre las clases políticas de todas las tenencias ${ }^{8}$. Sea como vigilantes de comicios electorales que prometían ser fraudulentos; sea como apoyo de oligarquías poderosas que se negaban a dejar el poder, como en el caso de Argentina antes de Perón; sea como auxilio de los sectores populares, imponiendo reformas institucionales que favorecieron a estos sectores como en el caso de Chile hasta 1920 y de Argentina durante el peronismo, Bolivia y Brasil, en las primeras décadas del siglo XX, o como en el Ecuador esgrimiendo un carácter anti-oligárquico y reformista, el papel político de la institución militar fue un dato constante.

Los analistas han denominado a este fenómeno político-militarcomo "La pauta Mediadora", "mecanismo de mediación" o "control militar $^{9}$. En la práctica significó la quiebra del modelo liberal de relaciones civil-militares y un impedimento para la profesionalización militar. Recordemos que antes de la Segunda Guerra Mundial, la hegemonía inglesa no implicó ninguna suerte de alianzas militares e ideológicas entre los países occidentales; de modo que en el desarrollo de las relaciones civil-militares en América Latina incidieron, en mayor medida, las condiciones nacionales.

Luego de la Segunda Guerra Mundial, la política exterior de nuestros países, las doctrinas de seguridad y muchos determinantes

Alain Rouquié: El Estado Militar en América Latina, México, Siglo XXI, 1971.

${ }^{8}$ Alain Rouquieu, Op. cit.

${ }^{9}$ Alfred Stepan. Op. cit. Y García Gallegos Bertha: Militares, Economía y Lucha Política, El Colegio de México, 1987. 
de la organización y entrenamiento de nuestros ejércitos fueron influenciados, de acuerdo con los condicionantes estratégicos propios, por la política exterior de los Estados Unidos y las diversas variantes de la doctrina de contrainsurgencia, o de contención del comunismo. Al contrario de lo que ocurría en la hegemonía inglesa, la nueva situación favoreció una mayor relación de los ejércitos nacionales con los Estados Unidos como potencia hegemónica, armándose un eje militar hemisférico importante, factor que acentuó el distanciamiento entre los ejércitos y sus respectivas sociedades, tanto a nivel interno de los países como a nivel regional.

Este distanciamiento, de acuerdo con análisis recientes, incidió en el atraso del desarrollo democrático y del potencial del desarrollo jurídico de nuestros estados. Durante períodos más o menos largos, durante las dictaduras militares, se puso a las fuerzas políticas fuera de juego, se reprimió las ideas y las libertades y se afectó por esta vía la capacidad de innovación de las instituciones políticas. Estos factores estorbaron también a los procesos de profesionalización de las Fuerzas Armadas, al interferir en la pauta subjetiva y objetiva de subordinación militar al poder civil, punto crucial de la profesionalización de la sociedad en general, y militar en particular.

En la sociedad contemporánea, compleja y diversificada, esta es posible únicamente en condiciones de pleno funcionamiento del Estado de derecho.

En América Latina, la verdadera preocupación por la profesionalización militar surgió a partir de los procesos de democratización, luego de los períodos de dictadura y como condición para superar las barreras que quedaron entre civiles y militares. La profesionalización misma ha sido un proceso difícil que ha requerido enormes esfuerzos y comprensión de las partes. Los resultados han sido diferentes según los casos y en general puede decirse que quienes más han avanzado han sido los estados que comprometieron mayores dosis de participación civil, especialmente partidos y legislaturas. Aquellos que lograron una mejor arquitectura en el desarrollo de mecanismos avanzados para la administración política civil, como es el caso de los ministerios civiles de defensa, las 
instancias de asesoría civil de esos ministerios, las formas de control de los parlamentos y en general, las debidas conexiones entre la administración civil y la jefatura militar.

\section{LAS RELACIONES CIVIL-MILITARES EN EL ECUADOR}

En Ecuador ocurren procesos semejantes a los de América Latina, en cuanto a las modalidades clásicas del desarrollo de las relaciones civil-militares. Luego de un largo período de caudillismo, el Ejército ecuatoriano fue formado bajo los parámetros del modelo liberal profesional. Factores estructurales que tienen que ver con la composición social, la inserción en la economía mundial un tanto residual como país agro exportador por mucho tiempo, y factores del desarrollo político, han modelado también el curso y potencialidades de nuestras Fuerzas Armadas y en gran medida, como veremos, han impedido la consolidación del proceso de profesionalización militar. Al aumentar las demandas sociales por servicios distintos a sus misiones específicas se ha terminado por formar un "ejército polivalente" no profesional. Hay que reconocer que la extracción popular de las FFAA ecuatorianas es uno de sus puntos más altos y fuente de su eficacia en la defensa del patrimonio nacional, puesto que en los sectores populares se han concentrado preferentemente el amor a la Patria y la disposición al sacrificio por su defensa y este es, sin duda, nuestro valor más importante como nación.

Esta fusión de valores entre el pueblo ecuatoriano y sus Fuerzas Armadas es uno de los factores constitutivos de las relaciones civil-militares en el Ecuador. Un segundo factor es el impacto del conflicto territorial con el Perú sostenido desde 1930 cuando se constituyó como Estado independiente, hasta 1999, cuando suscribió con el Perú el Tratado de Paz. El tercero es también el impacto prolongado del populismo. Un cuarto factor tiene que ver con el carácter de las relaciones hemisféricas que comparte nuestro país con el resto de la Región.

Atendiendo a estos tres factores constitutivos y solo para facilitar la exposición podríamos proponer una periodización muy arbitraria del desarrollo de las relaciones civil-militares en Ecuador: 
1. Formación del Estado nacional y modelo liberal de relaciones civil-militares. Hasta la Guerra de 1941 con el Perú. La primera politización.

2. Formación del Proyecto Militar. Desde 1941 hasta 1989. Contiene aspectos como la relación con el velasquismo; las etapas de formación del Proyecto militarde desarrollo nacional; los gobiernos militares; los procesos de institucionalización y profesionalización militar autónoma (Legislación Militar). El tardío desarroIlo nacional hacia adentro basado en el petróleo, durante la década de 1970-1979 significó grandes desfases con respecto a los procesos de desarrollo mundial. El desarrollo político propiciado por la presencia de nuevos partidos, a partir de 1976, no incluyó la formación de proyectos partidistas sobre defensa y Fuerzas Armadas.

3. Autonomía, corporativismo y expansión de misiones. Desde 1989 hasta 1999. La nueva diversificación política interna aportada por el movimiento indígena, trajo nuevas tensiones políticas que no recibieron una respuesta constrictiva de los militares, encargados en este país de la seguridad interna. Al contrario, esa respuesta significó el incremento vertiginoso de tareas no militares para atender a las poblaciones indígenas en su desarrollo social y económico. En cuanto a la política exterior, el final de la Guerra Fría impulsó un breve período de democratización- profesionalización militar (modelo de nueva profesionalización) que no alcanzó a equipararse en el Ecuador por causa de la inestabilidad política en que entró el país desde 1998.

4. Crisis y nueva articulación político militar frente a la guerra internacional contra el terrorismo. Las secuelas del proceso de paz con el Perú dentro de Fuerzas Armadas produjeron una conmoción y ha significado, en la práctica, el fin del acuerdo tácito entre Fuerzas Armadas y sociedad en torno al carácter reservado de los asuntos de defensa. Se produjo un proceso que bien podemos llamar de "Desacralización" de las Fuerzas Armadas. Las secuelas del 11 de septiembre de 2001 y la perspectiva del imperio unipolar que otorga un nuevo papel a las Fuerzas Armadas de los países periféricos ante el peligro de las amenazas asimétricas (Teoría de los "estados fracasados") ha producido 
una marcha atrás en los leves procesos de democratización de las relaciones civil-militares detectados antes. Avances al futuro dependerán del esfuerzo por lograr acuerdos civil-militares internos en torno a la consolidación del estado de derecho.

\section{DESARROLLEMOS LAS LÍNEAS DEL CUADRO ANTERIOR:} Formación del estado nacional y el modelo liberal de relaciones civil-militares. A grandes trazos: en el primer período tenemos la formación del Estado y del Ejército Nacional, incluidos en el pensamiento anticaudillista de Rocafuerte, García Moreno y Eloy Alfaro. La necesidad de un ejército institucional era evidente frente a los recurrentes problemas territoriales con el Perú. En la segunda y tercera década del siglo $X X$ se acentuaron la institucionalización de las Fuerzas Armadas con influencia europea (francesa). La pauta liberal de subordinación y obediencia militar al poder civil quedó impresa en las constituciones, aunque no se llegaron a cumplir en la práctica. Los militares se politizaron tempranamente y asumieron posiciones anti-oligárquicas, vinculándose con ideologías y partidos de izquierda (socialismo) y empujando procesos de reforma social y proyectos institucionales, como la organización de la Policía entre otros.

Formación del proyecto militar y desarrollo nacional. Desde 1941 hasta 1989. Después del conflicto bélico con el Perú, se consagró el distanciamiento de las FFAA con la clase política, que es desde entonces una constante en las relaciones civil-militares. Las fuerzas armadas empezaron a jugar como un elemento más del sistema político, pero independiente de los partidos. Esto es, han asumido el papel de un partido de Estado que empezó a delinear su propio Proyecto Nacional a raíz de la derrota frente al Perú, y a manejar su propio proyecto de institucionalización militar. El populismo velasquista interfirió en la institucionalización militar autónoma. Velasco entendió la importancia de controlar a las FFAA desde la política civil; No ocurrió lo mismo con los partidos Conservador y Liberal, ni con los adeptos velasquistas. Todos intentaron usar a los militares para sus particulares fines, "golpeando la puerta de los cuarteles". Contrario a su voluntad, Velasco politizó a las FFAA. usándolas para contener la insurrección popular y planteándoles una tensa relación en el nivel mismo del poder político, señalándoles con ello una vía de acceso al poder. Por su discurso 
abstracto y subyugante, el velasquismo (como todo fenómeno carismático) interfirió con los procesos de racionalización y profesionalización tanto de la administración del Estado como de las Fuerzas Armadas.

Las dictaduras de los años 1960 y 1970, pusieron en práctica aspectos del Proyecto Militar de desarrollo nacional y nueva institucionalización militar, con rasgos de la doctrina de contención del comunismo. Surgieron las instituciones militares de carácter civil (Escuela Superior Politécnica del Ejército e Instituto de Altos Estudios Nacionales). Se modernizó la tecnología militar; se propuso y perfeccionó la Legislación militar sin participación civil. En los años 1970 y tantos surgieron los partidos modernos de tendencia social demócrata y la derecha neoliberal, que impulsaron el retorno al poder civil. Ninguno de ellos desarrolló un proyecto civil de control y profesionalización militar. La izquierda, simpatizante o militante, se acercó al proyecto autónomo de los militares, sobre la base de una adhesión a las líneas del desarrollo social y político inducido desde el Estado y sin interferencia de los órganos de deliberación de la democracia los partidos y el Congreso. Se congeló el "distanciamiento prudente" de los civiles hacia los militares (Gobiernos de Oswaldo Hurtado Larrea, Rodrigo Borja Cevallos). La derecha (con León Febres Cordero) los manipuló y el Gobierno de Sixto Durán-Ballén sufrió las presiones de "baja intensidad" esgrimidas por la cúpula militar.

En todo el período, militares y civiles, se ensimismaron en el desarrollo nacional. Ninguno construyó una visión del país frente a la internacionalización y globalización en la que estaba inserto ya el resto del mundo. Esto significó el desfase del Ecuador respecto de las variables externas ya entonces determinantes.

Autonomía, corporativismo y expansión de misiones. Desde 1989 hasta el 11 de septiembre. A comienzos de los noventa el fin del Socialismo y de la Guerra Fría impactaron al mundo. A nivel interno, irrumpió el movimiento indígena organizado, con un proyecto de nueva izquierda (no marxista) en el plano político. Como resultado del alejamiento de la política (en los años 1980 y tantos) la victoria ecuatoriana en la Guerra del Cenepa, en 1995, demostró la eficacia militar. Estos sucesos acentuaron la diversificación de 
misiones no militares por parte de las FFAA en el desarrollo comunitario, dentro de una perspectiva de contención de la insurrección indígena. El proceso implicó un cambio de perspectiva en las Fuerzas Armadas a propósito del desarrollo: desde la macro planificación del los años 1970, al micro proyecto.

Desde la caída del Presidente Bucaram, en febrero de 1997 se aumentaron las demandas políticas distorsionadas de la población civil hacia las Fuerzas Armadas desde el campo civil, por orden y gobernabilidad. Se hizo evidente la ausencia de una política militar por parte de la clase política. Concomitantemente con esto se experimentó una nueva fase en la diversificación de estudios y tareas de los oficiales en temas ámbitos no militares. Esta "carrerización"empieza a ser funcional para los procesos de ascenso en la carrera militar y puede ser un factor detrás de la desprofesionalización actual de las Fuerzas Armadas.

Crisis y nueva articulación político-militar frente a la guerra internacional contra el terrorismo. Las Fuerzas Armadas acusan hoy los impactos de haberse convertido en una institución corporativa y contaminada de populismo. El triunfo de Lucio Gutiérrez en las elecciones de octubre y noviembre de 2002 ha aportado con un proceso de distorsión de la política que implica la presencia de un partido militar (Sociedad Patriótica). Se hace evidente el distanciamiento legal de las actividades militares básicamente no integradas al sistema de jurisdicción unitaria que propone la Constitución de 1998. No existen normativas claras que rijan la conducta profesional de los militares, ni sus derechos civiles y profesionales. Se utiliza a militares en servicio activo en tareas administrativas civiles. Se acusa el atraso de la legislación militar que no incluye las nuevas perspectivas estratégicas y de conflicto interno e internacional. Un proceso de desinstitucionalización y desprofesionalización parece inminente. Sin la contraparte fundamental del control civil a través de un marco jurídico apropiado, sin transparencia sobre los asuntos militares, y sin el concurso de la responsabilidad civil apoyada por una discusión abierta sobre problemas y soluciones, las Fuerzas Armadas pueden perder el rumbo institucional. 


\section{CONCLUSIONES}

La opción es el fortalecimiento del Estado de Derecho, ello implica promover las garantías para civiles y militares de acuerdo con su condición. Practicar una vinculación dinámica entre todas las instituciones del Estado y sectores de la Sociedad. Entre civiles y militares, buscando identificar los problemas, tratando de resolverlos con el aporte de las debidas responsabilidades indicadas por la Ley. Fortalecer la participación responsabilidad civil que corresponde al control civil de las políticas de defensa y militar. Desarrollar la administración civil de las políticas de defensa con la eficacia instrumental que requieren las demás políticas del Estado. Es necesario promover la responsabilidad de los partidos en la formulación de opciones de política de defensa y militar. Ninguna democracia moderna funciona sin partidos políticos. No aportamos a la coherencia política y jurídica del Estado promoviendo el populismo y el "movimientismo"que corresponden al ejercicio irresponsable y no consecuente de la cuestión política, sin aportar a los procesos de institucionalización que son cruciales para nuestros países. En cuanto a seguridad y defensa, necesitamos una doctrina del Estado de Derecho que distinga claramente entre las tareas de la Defensa, de seguridad como política exterior y de seguridad ciudadana; dentro de ella una doctrina de empleo de las fuerzas militares; normas claras sobre lo que deben hacer y no deben hacer las Fuerzas Armadas, por igual en tiempos de paz y en tiempos de conflicto, para evitar la recurrencia a las "situaciones de emergencia" que deben ser desterradas de las prácticas políticas y estratégicas.

David Pion Berlin, estudioso norteamericano sobre la cuestión militar en América Latina anota lo siguiente: "Las fuerzas armadas latinoamericanas se encuentran en una encrucijada entre el conjunto de tratados y medidas multilaterales de orden internacional que tratan de limitar su influencia política y las presiones de orden doméstico, para que asuman un papel en los conflictos. Las democracias están bajo estrés, tienen signos de fatiga y fragilidad por pobres gobiernos y pobres economias. Si hay una nación en donde hubiéramos esperado un rol expandido de las Fuerzas Armadas, este sería Argentina. Pero en el curso de 15 años esta nación ha construido limitaciones legales a la intervención militar en asun- 
tos domésticos. Sus leyes de Defensa nacional, reestructuración de la Inteligencia, demarcaron claramente los roles profesionales $y$ restringieron el involucramiento de los militares en estas materias. La misión de las fuerzas armadas es, por ley, la de defender a la nación contra las amenazas de origen externo únicamente. De ninguna manera ellas pueden indoctrinar o prepararse a símismas para misiones de seguridad interna. Pueden ser un soporte logístico de fuerzas de seguridad interna, en casos excepcionales cuando la Policía u otra fuerza de seguridad es rebasada por agresores armados y ello solo bajo estrictas provisiones establecidas por la Ley. Argentina ha soportado la crisis más grave de su historia. Pero la ausencia de los militares durante toda esta crisis es una nueva y esperanzadora noticia" 10.

Es justamente acerca de estos temas que debemos hablar los civiles y los militares, dentro de una acción política y académica. Afuera debe quedar cualquier intento de activismo.

${ }^{10}$ David, Pion Berlin. Between Regional Strength and Domestic Stress: A New Civil-Military Pragmatism in Latin America. Department of Political Science, University of California, Riverside david.pion@ucr.edu. 